\title{
Concepção de Ativos: Um Estudo sobre a Compreensão dos Discentes do Curso de Graduação em Ciências Contábeis da UFERSA
}

\section{Conception Of Assets: A Study About the Comprehension of the Students From Accounting Graduation Course From UFERSA}

\section{Concepción de Activos: Un Estudio Acerca de la Comprensión de Los Estudiantes de Pregrado en Ciencias Contables de la UFERSA}

\author{
Luiz Cláudio Alves Moura \\ Rua Engenheiro Carlos Dunaresque, 26, Alto de São Manoel, CEP 59.631-210 - Mossoró-RN \\ Graduado pela UFERSA
}

Thaiseany de Freitas Rêgo

Av. Francisco Mota, 572, Costa e Silva, CEP 59.625-900 - Mossoró-RN

Mestre em Contabilidade pela UnB/UFPB/UFRN

Doutoranda em Administração pela PUC-PR

Professora Assistente II da UFERSA

\begin{abstract}
RESUMO
Na Contabilidade, as contas de ativo têm assumido diversas compreensões em razão dos aspectos teóricos e normativos. O estudo objetivou investigar a concepção dos discentes do curso de graduação em Ciências Contábeis da UFERSA sobre os ativos. Para tanto, adotou-se a pesquisa de campo, com a aplicação de um instrumento de coleta, tratando sobre o perfil dos discentes, apresentando informações gerais sobre ativos (definição, reconhecimento, mensuração e evidenciação) e o processo de classificação desses itens (circulante, não circulante, tangível, intangível), tanto sob o aspecto teórico como normativo. A pesquisa observa uma amostragem não probabilística por acessibilidade, que resultou em 128 questionários válidos. Os dados obtidos foram tabulados no software SPSS 19.0®, de modo a subsidiar a análise exploratória e o uso da análise descritiva. O estudo revela a predominância de jovens, entre 16 e 24 anos, do gênero feminino no curso. Os respondentes, que já cursaram a disciplina de "Teoria da Contabilidade", indicam compreender a definição dos ativos sob a perspectiva normativa, enquanto que os demais seguem a linha teórica. Quanto ao reconhecimento, mensuração e evidenciação dos ativos, os discentes associam seus conhecimentos ao conteúdo do CPC 00-R1. De modo geral, apresentam dificuldade de diferenciar, adequadamente, os itens patrimoniais e de resultado, bem como de classificá-los em circulante, não circulante, tangível e intangível.
\end{abstract}

Palavras-chave: Definição de ativo. Reconhecimento e mensuração de ativos. Classificação dos ativos.

\footnotetext{
${ }^{1}$ Artigo recebido em 08.10.2013. Revisado pelos pares em 07.02.2014 (blind review). Ajustado e Aceito para publicação em 15.04.2014. Recomendado para publicação por José Ribamar Marques de Carvalho (Editor Científico). Publicado em 15.08.2014. Organização responsável UACC/CCJS/UFCG.
} 


\begin{abstract}
The assets have taken several accounting concepts because of theoretical and normative aspects in Accounting. The study aimed to investigate the Accounting Graduation Course students' conception about the Assets. In fact, field research was used with the application of a collection instrument dealing about the students' profile, showing general information about Assets (definition, acknowledgment, mensuration and disclosure) and the classification process of these items (current, fixed (noncurrent), tangible and intangible assets) both under theoretical and normative aspects. The research observes nonprobability sampling by accessibility, which had as result 128 valid questionnaires. The data obtained were charted on SPSS 19.0® software (Statistical Package for the Social Sciences 19.0®) in order to support the exploratory data analysis and the use of descriptive analysis. Data indicate that women aged between 16 and 24 years old are predominant in the course. Students, who have already attended the "Accounting Theory" class, understand the definitions of Assets under the normative view while others follow the theoretical discussion line. As to acknowledgement, mensuration and disclosure assets, students mingle their knowledge under the CCP 00 R-1 (Code of Civil Procedure 00 R-1) Generally, they have difficulty distinguishing appropriately the balance sheet and income statements, as well as to classify them into current, fixed (noncurrent), tangible and intangible.
\end{abstract}

Key-words: Definition of Assets. Acknowledgment and mensuration of Assets. Classification of Assets.

\title{
RESUMEN
}

En la contabilidad, las cuentas de activos han asumido diferentes interpretaciones debido a aspectos teóricos y normativos. Este estudio tuvo como objetivo investigar la concepción de los estudiantes de pregrado en Ciencias Contables de la UFERSA sobre los activos. Con este fin, hemos adoptado a la investigación de campo con la implementación de un instrumento de recolección de datos, tratando del perfil de los estudiantes, presentando informaciones generales sobre activos (definición, reconocimiento, medición y revelación) y el proceso de clasificación de tales items (circulante, no circulante, tangible, intangible), tanto bajo el aspecto teórico como el normativo. La pesquisa observa un muestreo no probabilístico por accesibilidad, lo que resultó en 128 cuestionarios válidos. Los datos fueron tabulados utilizando el software SPSS 19.0 ® con el fin de apoyar el análisis exploratorio y el uso del análisis descriptivo. El estudio muestra el predominio de los jóvenes de entre 16 y 24 años de edad, del género femenino en el curso. Los encuestados que ya habían estudiado el tema "Teoría de la Contabilidad", indican entender la definición de los activos bajo la perspectiva normativa, mientras que los otros siguen la línea teórica. Sobre el reconocimiento, la medición y la divulgación de activos, los estudiantes asocian sus conocimientos al contenido del CPC 00-R1. En general, presentan dificultad para diferenciar adecuadamente los items patrimoniales y de resultado, así como clasificarlos en activos circulantes, no circulantes, tangibles e intangibles.

Palabras clave: Definición de activo. Reconocimiento y medición de activos. Clasificación de los activos.

\section{INTRODUÇÃO}

A cultura abrange concepções sobre a construção dos saberes, fazeres, valores, regras de conduta, crenças e mitos, de acordo com a evolução histórica do homem. Tais conjecturas são expressas por meio de símbolos tangíveis e intangíveis, sendo transmitidas e reproduzidas entre as gerações. A cultura respalda a existência da sociedade, bem como as atividades em relação à vida, o que mantêm a complexidade das relações humanas (MORIN, 2000).

Iudícibus (2009) destaca a cultura como uma expressão das práticas de proteção, perpetuação e interpretação dos fatos como objetos materiais disponíveis ao homem. A história da civilização contribuiu sobremaneira para o surgimento da Contabilidade, uma das ciências sociais mais antigas e complexas, cujo objeto de estudo é o patrimônio. Antropologicamente, a Contabilidade se desenvolve 
considerando a perspectiva das necessidades de registro das atividades de comércio, mesmo antes da existência da escrita, números e moeda.

Ribeiro (2009b) trata a Contabilidade como uma ciência cujas técnicas, possibilitam o controle do patrimônio das organizações, sejam elas do primeiro, segundo ou terceiro setor. Ott e Pires (2009) a destaca como uma ciência integrante de um complexo sistema de informação, que extrapola as exigências fiscais. Isso ocorre em razão da Contabilidade ter a preocupação em estudar a composição da riqueza patrimonial e gerar informações úteis, voltadas ao planejamento das atividades da organização e à tomada de decisão.

A Contabilidade tem o propósito de cuidar dos aspectos econômicos, financeiros e patrimoniais de uma organização, sendo a mesma expressa monetariamente em bens, direitos e obrigações. Nesse contexto, a Teoria Contábil revela o quanto as definições dos elementos que compõem os relatórios empresariais é essencial para fundamentar as bases da Contabilidade.

$\mathrm{O}$ estudo restringe-se à compreensão dos discentes quanto à abordagem das contas de ativo, representadas por bens e direitos. Esses itens são apresentados no Balanço Patrimonial em ordem decrescente, de acordo com o grau de liquidez, estando dividido em dois grandes grupos: circulante e não circulante. Os ativos configuram-se como um campo de discussão próprio da "Teoria da Contabilidade". Dentre os pontos abordados destacam-se o seu caráter conceitual e as prerrogativas referentes ao reconhecimento, mensuração, evidenciação e classificação. Ribeiro (2009b, p. 60) aponta os ativos como um elemento de "fundamental importância, não somente para os profissionais da área, mas também para todos aqueles que fazem uso da Contabilidade".

Considerando o exposto e as divergências inerentes ao que rezam os aspectos teóricos e normativos dos ativos, o presente estudo busca responder ao seguinte problema de pesquisa: "Qual a concepção dos discentes do curso de graduação em Ciências Contábeis da UFERSA sobre os ativos?". Em termos teóricos, cabe destacar a preocupação em se discutir como ocorre o processo de reconhecimento, mensuração e evidenciação dos ativos. No que diz respeito à normatização, a mesma volta-se às questões da classificação e evidenciação, como trata a Lei n. ${ }^{\circ}$ 6.404/1976, Lei n. ำ 11.638/2007 e o Comitê de Pronunciamentos Contábeis (CPC).

O estudo objetiva investigar qual a concepção dos discentes do curso de graduação em Ciências Contábeis da UFERSA sobre os ativos. O mesmo configura-se como um elemento importante para as organizações, uma vez que propiciam o seu desenvolvimento econômico, patrimonial e financeiro. No que concerne à concepção dos ativos, o estudo fez-se uso dos pontos abordados na "Teoria da Contabilidade" (HENDRIKSEN; VAN BREDA, 2009; NIYAMA; SILVA, 2011) e nas normas vigentes (Lei n. ${ }^{\circ}$ 6.404/1976; CPC 00-R1, 2011), bem como das diretrizes traçadas por Goulart (2002). 


\section{FUNDAMENTAÇÃO TEÓRICA}

Aqui são discutidos alguns aspectos referentes à definição conceitual dos ativos e suas principais características. Aborda-se o processo de reconhecimento, mensuração e evidenciação dos ativos, bem como a sua classificação.

\subsection{DEFINIÇÕES E CARACTERÍSTICAS DOS ATIVOS}

Ribeiro (2010a) aponta a Contabilidade como uma ciência social, cujo propósito consiste em orientar, controlar e registrar os eventos relativos à gestão de uma organização. Essa ciência deve ser compreendida como um sistema, capaz de fornecer informações apropriadas ao atendimento dos interesses de seus usuários. A Contabilidade representa uma ferramenta que auxilia o processo de gestão e propicia retornos, no sentido de delinear o modo como os investimentos são utilizados.

Niyama e Silva (2011, p. 114) comentam que o "ativo é um recurso controlado pela entidade como resultado de eventos passados e do qual se espera que resultem futuros benefícios econômicos para a entidade". Para Lustosa (2009), o ativo visa angariar resultados, dos quais se espera obter retorno. Os ativos observam a disponibilidade de patrimônio, a fim de gerenciar os recursos com base em eventos passados, e auferir benefícios futuros.

As contas de ativo devem ser dispostas em ordem decrescente, conforme o grau de liquidez, para facilitar a observação dos prazos de recebimento e a questão da tangibilidade. Iudícibus (2009) destaca que os ativos precisam incorporar algumas características essenciais: poder de troca, direito de propriedade e potencial gerador de recursos econômicos. Ponderando sobre os pontos levantados, e analisando as definições apresentadas pelos mais diversos autores da área contábil, pode-se verificar que o Quadro 1 elenca uma série de definições.

\begin{tabular}{|c|l|}
\hline Aspectos & \multicolumn{1}{c|}{ Definições } \\
\hline \multirow{3}{*}{ Introdutórios } & $\begin{array}{l}\text { O ativo representa, de forma estática, os bens e os direitos da entidade, ou seja, tudo o } \\
\text { que a empresa possui e que lhe é devido (SZUSTER } \text { et al., 2010). }\end{array}$ \\
\cline { 2 - 2 } Avançados & $\begin{array}{l}\text { Renjunto de bens e direitos controlados pela empresa (IUDÍCIBUS, 2009). } \\
\text { espera que resultem futuros benefícios econômicos para a entidade (NIYAMA; } \\
\text { SILVA, 2011). }\end{array}$ \\
\cline { 2 - 2 } & $\begin{array}{l}\text { Potenciais fluxos de serviço ou direitos a benefícios futuros sob o controle de uma } \\
\text { organização (HENDRIKSEN; VAN BREDA, 2009). }\end{array}$ \\
\hline \multirow{3}{*}{ Normativos } & Recursos disponíveis, direitos e participações (Lei n. $6.404 / 1976)$. \\
\cline { 2 - 2 } & $\begin{array}{l}\text { Recurso controlado pela entidade como resultado de eventos passados e do qual se } \\
\text { espera que fluam futuros benefícios econômicos para a entidade (CPC 00-R1, 2011). }\end{array}$ \\
\hline Científicos & $\begin{array}{l}\text { A capacidade de prestar serviços futuros à entidade que os controla, representando } \\
\text { uma "promessa futura de caixa" (GOULART, 2002). }\end{array}$ \\
\hline
\end{tabular}

Quadro 1: Definições de ativos.

Fonte: Dados da pesquisa (2013). 
Na essência, os ativos devem ter um valor de aquisição e gerar benefícios econômicos futuros (LIMA FILHO; BRUNI, 2012). Hendriksen e Van Breda (2009) comentam que a sua classificação precisa observar o poder de conversão desses itens em recursos financeiros, considerando o curso normal dos negócios. Iudicíbus (2009) chama atenção para a sua capacidade de prestar serviços futuros à entidade ou de representar uma promessa futura de caixa.

Para Iudicíbus (2009) os ativos sinalizam, mediata ou imediatamente, uma promessa futura de caixa. Nessa perspectiva, os mesmos representam uma oportunidade para a empresa gerar e aplicar seus recursos em bens, tangíveis e intangíveis, de curto prazo e longo prazo. As contas de ativo somam recursos e direitos de recebimentos, que se encontra em propriedade da empresa.

\subsection{RECONHECIMENTO, MENSURAÇÃO E EVIDENCIAÇÃO}

Os itens que compõem o ativo devem ser reconhecidos quando têm potencial para gerar benefícios econômicos futuros. Esses elementos devem fluir para a entidade, caso o seu custo ou valor venha a ser mensurado com confiabilidade. $\mathrm{O}$ processo de evidenciação acontece quando esses itens tomam forma e são apresentados nos relatórios empresariais da organização (CPC 00-R1, 2011).

Segundo Niyama e Silva (2011) o processo de reconhecimento dos ativos se dá com a sua incorporação nas demonstrações contábeis obrigatórias, com destaque para o Balanço patrimonial. O referido instrumento se propõe a retratar a situação patrimonial da organização, em termos de ativos (bens e direitos), passivos (obrigações com terceiros) e patrimônio líquido (obrigações com os sócios). Os ativos se destacam por retratar benefícios futuros gerenciais, capazes de proporcionar as condições mínimas para a sustentabilidade e competitividade organizacional.

A determinação do custo ou valor dos ativos precisa respalda-se em documentos hábeis e atender as características qualitativas da informação. A confiabilidade é uma das características a serem observadas, no sentido de assegurar aos usuários, as condições necessárias para a tomada de decisão. Considerando esses aspectos, destacam-se algumas definições importantes sobre reconhecimento, mensuração e evidenciação, como ilustrado no Quadro 2.

\begin{tabular}{|l|l|}
\hline \multicolumn{1}{|c|}{ Itens } & \multicolumn{1}{c|}{ Definiçães } \\
\hline \multirow{5}{*}{ Reconhecimento } & $\begin{array}{l}\text { Reconhecido quando for provável que benefícios econômicos futuros dele } \\
\text { provenientes fluirão para a entidade e seu custo ou valor puder ser mensurado } \\
\text { com confiabilidade (CPC 00-R1, 2011). }\end{array}$ \\
\cline { 2 - 2 } & \begin{tabular}{l} 
Reconhecido com base no fato gerador (NIYAMA; SILVA, 2011). \\
\cline { 2 - 3 } \\
Reconhecido quando satisfaz a definição de ativo e passa por testes de relevância e \\
confiabilidade (HENDRIKSEN; VAN BREDA, 2009).
\end{tabular} \\
\hline Mensuração & $\begin{array}{l}\text { Com base no valor justo, custo de aquisição (emissão ou produção) e valor } \\
\text { presente (Lei n.. 6.404/1976). }\end{array}$ \\
\hline
\end{tabular}




\begin{tabular}{|c|c|}
\hline & $\begin{array}{l}\text { Com base no custo histórico, custo corrente, valor realizável (valor de realização } \\
\text { ou de liquidação) e valor presente (CPC 00-R1, 2011). }\end{array}$ \\
\hline & Com base no custo histórico (LUSTOSA, 2009). \\
\hline & $\begin{array}{l}\text { Com base em medidas de entrada (custo histórico, custo de reposição, custos } \\
\text { esperados) e de saída (preço de venda passado, preço corrente de venda, valor } \\
\text { realizável esperado) (HENDRIKSEN; VAN BREDA, 2009). }\end{array}$ \\
\hline \multirow{4}{*}{ Evidenciação } & $\begin{array}{l}\text { Divulgar informações financeiras no Balanço, em ordem decrescente de grau de } \\
\text { liquidez dos elementos registrado em ativo circulante e ativo não circulante (Lei } \\
\text { n. } 6.404 / 1976 \text { ). }\end{array}$ \\
\hline & $\begin{array}{l}\text { Divulgar informações financeiras no Balanço patrimonial, de modo a torná-la } \\
\text { clara, concisa e compreensível (CPC 00-R1, 2011). }\end{array}$ \\
\hline & $\begin{array}{l}\text { Divulgar informações financeiras no Balanço patrimonial, de acordo com o grau } \\
\text { de liquidez (SZUSTER et al., 2010). }\end{array}$ \\
\hline & $\begin{array}{l}\text { Divulgar informações financeiras úteis ao processo de tomada de decisão } \\
\text { (HENDRIKSEN; VAN BREDA, 2009). }\end{array}$ \\
\hline
\end{tabular}

Quadro 2: Definições de reconhecimento, mensuração e evidenciação.

Fonte: Dados da pesquisa (2013).

Lustosa (2009) aponta a mensuração ou avaliação dos ativos como um procedimento ao qual se atribui valor monetário a um bem ou direito. Para se atribuir esse valor, o reconhecimento do ativo é essencial, considerando a incompatibilidade de se medir algo que não se conhece (HENDRIKSEN; VAN BREDA, 2009). Nesse contexto, destaca-se a necessidade de compreender a mensuração como um processo, cuja preocupação reside na atribuição de valores de entrada ou saída (GUERREIRO et al., 2005; LIMA FILHO; BRUNI, 2012).

Segundo Perez e Famá (2006) a globalização e os avanços da tecnologia da informação têm facilitado a disseminação do conhecimento, o que provoca alterações no ambiente organizacional. Essas mudanças têm condicionado o processo de geração de riqueza, apesar de a simples existência de um ativo não ser suficiente para a Contabilidade reconhecê-lo. As informações fornecidas pela Contabilidade precisam ser trabalhadas, no sentido de se antecipar aos acontecimentos que podem influenciar o processo de tomada de decisão dos potenciais usuários da informação.

Iudícibus (2009) aponta que a evidenciação auxilia os usuários no processo de tomada de decisão, seja ela de cunho financeiro, econômico ou patrimonial. Essas informações devem ser organizadas de modo a atender ao perfil, necessidade, relevância e demanda de qualquer tipo de usuário, stakeholders. A evidenciação representa um compromisso inalienável do profissional de Contabilidade com o fornecimento de informações úteis para a tomada de decisão. Alguns estudos destacam a necessidade de adoção de práticas de divulgação que propiciem a transparência quanto ao tratamento dado aos ativos, como o teste de recuperabilidade (impairtment), recomendado tanto para organizações do primeiro setor (CARVALHO et al., 2012) como do segundo (PONTES et al., 2011).

Dentre os métodos utilizados na evidenciação, destacam-se as demonstrações contábeis e os relatórios empresariais (AVELINO et al., 2012). Na essência, esse 
processo possibilita a organização de elementos quantitativos e qualitativos, de modo a dispor de informações úteis para a análise dos usuários. Nessa perspectiva, em momentos de decisão, a atribuição de valores permite a compreensão da essência da informação, cuja característica volta-se ao atendimento dos objetivos organizacionais (VASCONCELOS; VIANA, 2002).

\subsection{CLASSIFICAÇÃO DOS ATIVOS}

Os ativos são comumente distribuídos em dois grandes grupos: itens circulantes, de curto prazo; e itens não circulantes, de longo prazo. Os itens que compõem o ativo circulante são aqueles que podem ser consumidos ou transformados em recursos financeiros até o início do exercício subsequente. Já os itens que figuram como não circulantes só podem se transformar em recursos financeiros após o exercício social seguinte.

A classificação dos ativos também se configura como um ponto de discussão para a Contabilidade. Para tanto, consideram-se as perspectivas de tangibilidade e intangibilidade (SQUENA; PASUCH, 2010), bem como o seu tratamento como ativo corrente ou circulante e não corrente ou não circulante. Niyama e Silva (2011) apontam o ativo como um elemento, cujo propósito consiste em gerar benefícios futuros.

A disposição dos itens de ativo observa a associação dos recursos com o que se desejam empregar ou obter, no sentido de gerar benefícios econômicos futuros à organização. Lustosa (2009) esclarece que as contas de ativos tangíveis são associadas aos recursos físicos, já os intangíveis sinalizam recursos que não possuem representação física. A diferença entre esses itens reside nas peculiaridades concernentes a cada um deles e o seu potencial na geração de benefícios econômicos líquidos.

Ribeiro (2009) trata os intangíveis como bens incorpóreos, em razão dos mesmos não possuírem corpo físico para indicar sua materialidade. Para Assaf Neto (2010, p. 56) "o intangível compõe-se dos bens de propriedade industrial ou comercial legalmente conferido à empresa, originando-se disso seu valor, e não da propriedade física dos mesmos". Nessa perspectiva, o intangível representa contas que requerem uma atenção maior, em termos de zelo, quanto ao potencial de gerar benefícios futuros.

O termo intangível é subjetivo quanto à disponibilidade de bens e direitos, sendo o seu valor atribuído economicamente e financeiramente pelo mercado. Dentre os principais intangíveis, destacam-se o goodwill, marcas, patentes, direitos autorais e carteiras de clientes. Para Lustosa (2009, p. 100):

Ativos intangíveis seriam os recursos que não têm uma representação física, exemplo, o capital intelectual, a marca das empresas, o goodwill, [...] a condição de tangibilidade ou intangibilidade de um ativo não está 
relacionada com a natureza física do bem em si, mas na sua representação ou não no balanço patrimonial.

De acordo com a Lei n.o 6.404/1976, inciso VI, do art. 179, o intangível representa os bens incorpóreos destinados à conservação da companhia ou constituídos com essa finalidade. O CPC 04-R1, em seu item 11, destaca a definição de ativo como intangível, quando o mesmo é identificável, o diferenciando-o do ágio derivado da expectativa de rentabilidade futura (goodwill). Assim, os intangíveis precisam estar relacionados diretamente com os benefícios que serão despendidos por outros ativos tangíveis tomados em negociação e que são individualizados para não influenciar a rentabilidade futura (SQUENA; PASUCH, 2010). Dentre as classificações que os ativos podem assumir destacam-se as anunciadas no Quadro 3.

\begin{tabular}{|c|c|c|c|c|c|}
\hline \multirow{2}{*}{ Grupo } & \multirow{2}{*}{ Subgrupo } & \multicolumn{4}{|c|}{ Classificação } \\
\hline & & $\mathrm{AC}^{*}$ & $\mathrm{ANC}^{* *}$ & TAN $^{* * *}$ & $\mathrm{INT}^{* * * *}$ \\
\hline \multirow[t]{2}{*}{ Disponível } & $\begin{array}{l}\text { Aplicações de liquidez } \\
\text { imediata }\end{array}$ & $x$ & & & $x$ \\
\hline & Banco & $\mathrm{x}$ & & & $x$ \\
\hline \multirow{2}{*}{ Clientes } & Contas a receber & $x$ & & & $\mathrm{x}$ \\
\hline & Títulos a receber & $x$ & & & $x$ \\
\hline \multirow{2}{*}{ Estoque } & Mercadoria para revenda & $x$ & & $x$ & \\
\hline & Matéria Prima & $x$ & & $\mathrm{x}$ & \\
\hline \multirow{2}{*}{ Despesas antecipadas } & Seguro diferido & $x$ & & & $\mathrm{x}$ \\
\hline & Aluguel diferido & $x$ & & & $x$ \\
\hline \multirow{2}{*}{$\begin{array}{l}\text { Realizável a longo } \\
\text { prazo }\end{array}$} & Depósitos Judiciais & & $\mathrm{x}$ & & $x$ \\
\hline & $\begin{array}{l}\text { Empréstimos a Pessoas } \\
\text { Ligadas }\end{array}$ & & $x$ & & $x$ \\
\hline \multirow[b]{2}{*}{ Investimentos } & Participações Societárias & & $\mathrm{x}$ & & $x$ \\
\hline & $\begin{array}{l}\text { Imóveis Não Destinados ao } \\
\text { Uso }\end{array}$ & & $x$ & $x$ & \\
\hline \multirow{2}{*}{ Imobilizado } & Imóveis & & $x$ & $x$ & \\
\hline & Veículos & & $x$ & $\mathrm{x}$ & \\
\hline \multirow{2}{*}{ Intangível } & Fundo de Comércio & & $x$ & & $x$ \\
\hline & Marcas e Patentes & & $x$ & & $x$ \\
\hline
\end{tabular}

* AC: Ativo circulante. ${ }^{* *}$ ANC: Ativo não circulante. ${ }^{* * *}$ TAN: Tangível. ${ }^{* * *}$ INT: Intangível Quadro 3: Classificação dos itens de ativo

Fonte: Adaptado de Iudícibus (2009); Marion (2009); Lustosa (2009) e Assaf Neto (2010).

Hendriksen e Van Breda (2009) comentam que os itens de ativo podem ser classificados como circulantes ou não circulantes. $\mathrm{O}$ ativo circulante contempla um grupo de contas que possui maior disponibilidade de uso, sendo o mesmo organizado de acordo com o grau de liquidez. A alteração provocada nos itens dessa natureza se dá por meio da realização de transações de vendas ou do reconhecimento do desgaste causado pelo uso nas atividades operacionais da organização.

Marion (2009) aponta o ativo circulante ou corrente como bens e direitos de curto prazo. Os itens que atendem a essa classificação se caracterizam por retratar a 
situação dos elementos relacionados ao caixa e a outros disponíveis, sendo os recursos identificados com base na obtenção de um resultado financeiro imediato, em dinheiro. Hendriksen e Van Breda (2009, p. 345), revelam que o "Ativo circulante é definido como caixa e outros ativos ou recursos comumente identificados como sendo aqueles que razoavelmente se espera sejam realizados em dinheiro ou vendidos ou consumidos durante o ciclo operacional normal da empresa".

Marion (2009) analisa dois aspectos distintos ao tratar do ativo não circulante: o prazo a ser cumprido, que ocorre após o exercício seguinte, e a classificação de itens como vendas a receber, empréstimos a sociedade coligadas ou controladas. Para Szuster et al. (2010, p. 38) "o ativo representa de forma estática, os bens e os direitos da entidade, ou seja, tudo o que a empresa possui (caixa, máquinas, prédios, terrenos, estoques, material de escritório, etc.) e tudo o que lhe é devido (contas a receber)".

As contas classificadas no ativo não circulante abarcam bens e direitos, cujos benefícios ou recebimentos só ocorreram no exercício seguinte. Segundo Assaf Neto (2010), o ativo não circulante inclui itens de baixa liquidez e lenta transformação em dinheiro. Como os mesmos não se destinam a venda, mas a operacionalização das atividades da organização, a sua liquidez é baixa. Ferreira (2009) considera os ativos não circulantes como direitos realizáveis no longo prazo ou bens de uso permanente.

Marion (2006) inclui no ativo não circulante, os itens cujos valores são realizáveis após o término do exercício social posterior a publicação do Balanço patrimonial, e aqueles valores cujo prazo de realização seja considerado duvidoso ou incerto. O item 67 do CPC 26-R1 (2011), utiliza a expressão "não circulante", para os ativos tangíveis, intangíveis e financeiros de longo prazo. O valor empregado no não circulante observa o custo dos bens utilizados pela organização em suas atividades operacionais.

O CPC 26-R1 (2011) destaca os ativos não circulantes como itens a serem mantidos pela organização para o desenvolvimento de suas atividades operacionais, em condições de continuidade, e mantidos para venda, em processo de descontinuidade. $\mathrm{O}$ referido instrumento também normatiza os problemas de avaliação, classificação e evidenciação dos bens e diretos de curto e longo prazo: disponibilidades, estoques, investimentos, imobilizados e intangíveis. Tal fato permite a compreensão dos preceitos inerentes aos ativos, bem como das situações em que esses itens podem ser debitados e/ou creditados.

\section{PROCEDIMENTOS METODOLÓGICOS}

O estudo objetivou investigar qual a concepção dos discentes do curso de graduação em Ciências Contábeis da UFERSA sobre os ativos. Para isso, fez-se uso da pesquisa de campo, bem como das análises descritiva e explicativa. Segundo Silva e Menezes (2001) essas estratégias requerem a utilização de técnicas padronizadas de 
coleta de dados, como o questionário e a observação. Nessa perspectiva, foi construído um questionário como instrumento de coleta, contemplando três blocos de perguntas, como pode ser observado no Quadro 4:

\begin{tabular}{|c|c|}
\hline Blocos & Principais autores \\
\hline Bloco A: Perfil do respondente & Goulart (2002), Rêgo e Andrade (2010) \\
\hline $\begin{array}{c}\text { Bloco B: Conhecimentos gerais } \\
\text { sobre os ativos }\end{array}$ & $\begin{array}{c}\text { Lei n. }{ }^{\circ} \text { 6.404/1976, Goulart (2002), Hendriksen e Van Breda (2009), } \\
\text { Iudícibus (2009), CPC 00-R1 (2011), Lustosa (2009), Szuster et al. } \\
(2010), \text { Niyama e Silva (2011) }\end{array}$ \\
\hline $\begin{array}{c}\text { Bloco C: Classificação dos } \\
\text { ativos }\end{array}$ & Iudícibus (2009), Marion (2009), Lustosa (2009), Assaf Neto (2010) \\
\hline
\end{tabular}

Quadro 4: Formação dos questionamentos.

Fonte: Dados da pesquisa (2013).

Os discentes regularmente matriculados no curso de graduação em Ciências Contábeis da UFERSA, situado no Município de Mossoró/RN, foram definidos como os sujeitos de análise. A referida Instituição de Ensino Superior (IES) foi criada após diversas discussões políticas, mediante a incorporação da Escola Superior de Agricultura de Mossoró (ESAM) à rede federal de ensino superior (Lei n.. 11.155/2005), o que proporcionou o aumento na disseminação do conhecimento superior na região, bem como o desenvolvimento em termos de atividades de ensino, pesquisa e extensão. Já o curso de graduação em Ciências Contábeis, iniciou suas atividades em 2009 e teve sua primeira turma de egressos formada no primeiro semestre letivo do ano de 2013.

O propósito do curso é formar profissionais devidamente preparados para a resolução de situações-problema e antenados aos aspectos teóricos e normativos da Ciência Contábil. Os docentes que ministram os componentes curriculares na área de formação profissional possuem, pelo menos, formação básica na área das Ciências Contábeis e o título de mestre em Contabilidade ou Engenharia de produção (PPCCC, 2012). Tal fato possibilita a discussão, em sala, de aspectos teóricos e normativos sobre a definição, reconhecimento, mensuração, evidenciação e classificação dos itens que compõem os ativos. O curso destaca-se por possuir dois ingressos anuais e receber semestralmente 40 discentes pelo Sistema de Seleção Unificada (SISU). Destaca-se que na época do estudo, o curso contava com 276 discentes regularmente matriculados, como pode ser visualizado na Tabela 1.

Tabela 1: Universo da pesquisa

\begin{tabular}{c|c|c|c}
\hline IES & Ano de ingresso & Matriculados & Respondentes \\
\hline \multirow{4}{*}{ UFERSA } & 2009 & 50 & 33 \\
\cline { 2 - 4 } & 2010 & 41 & 16 \\
\cline { 2 - 4 } & 2011 & 65 & 37 \\
\cline { 2 - 4 } & 2012 & 84 & 38 \\
\hline & 2013 & 36 & 21 \\
\hline
\end{tabular}

Fonte: Dados da pesquisa (2013). 
A delimitação dos sujeitos de análise considerou, ainda, o fato de o corpo docente do curso tratar sobre a concepção dos ativos desde o primeiro período, com o componente curricular de "Contabilidade introdutória", e desse assunto ser sedimentado no quarto período, com a "Teoria da Contabilidade". Nessa perspectiva, a amostra configura-se como do tipo não probabilística por acessibilidade, uma vez que considerou a disponibilidade dos docentes em permitir o acesso às salas de aula, bem como a presença e interesse dos discentes em participar da pesquisa (SAMARA; BARROS, 2002).

Os autores também se preocupam em fundamentar os achados, considerando o que trata a "Teoria da Contabilidade" e o esforço nacional de adequação as normas internacionais, como tratado na Lei n. ${ }^{\circ}$ 11.638/2007 e nos pronunciamentos emitidos pelo CPC. No que diz respeito à abordagem do problema, o presente estudo enquadra-se como do tipo quantitativo, uma vez que faz uso da estatística descritiva. Essa técnica foi empregada com o intuito de garantir condições mínimas de análise e reduzir possíveis distorções (DIEHL, 2004).

Os dados foram tabulados no software Statistic Professional Standard (SPSS®, versão 19.0), de modo a proceder com a análise exploratória e identificar possíveis dados faltantes ou discrepantes. Segundo Malhotra (2011) esse tipo de análise possibilita a exclusão de questionários que possuam variáveis desconhecidas ou ambíguas. O processo de coleta resultou em 145 questionários, dos quais 17 foram eliminados por apresentar problemas com dados faltantes, sendo 128 deles considerados válidos e aptos para seguir com a estatística descritiva (MALHOTRA, 2011).

\section{APRESENTAÇÃO E DISCUSSÃO DOS RESULTADOS}

Nessa seção são apresentados os principais achados do estudo: perfil dos respondentes, informações relativas a conhecimentos gerais sobre os ativos e sua classificação. Os dados foram organizados com o intuito de permitir analisar a concepção dos discentes que já cursaram o componente curricular de "Teoria da Contabilidade" e daqueles que ainda não tiveram a oportunidade de cursá-la.

\subsection{PERFIL DOS RESPONDENTES}

Os respondentes correspondem a 54,31\% dos discentes regularmente matriculados no curso de graduação em Ciências Contábeis da UFERSA e se encontram distribuídos entre o primeiro e o nono período. Considerando isso, destaca-se que a maioria dos respondentes se enquadram no gênero feminino e são jovens, com idade entre 16 e 24 anos. Tais dados corroboram com os estudos 
realizados por Rêgo e Andrade (2010) e Sá (2011), ao afirmarem que mais de 50\% dos discentes que ingressam nos cursos de graduação em Ciências Contábeis, são pessoas jovens e do gênero feminino.

Os achados podem ser explicados em razão de os jovens estarem ocupando um espaço cada vez maior em cursos de nível superior e a figura feminina estar buscando capacitação para a atuação profissional (RÊGO; ANDRADE, 2010). Segundo o CFC (2013) o Brasil tem aumentado o número de mulheres atuando em atividades de natureza contábil, nos últimos anos, saindo de 34,03\%, em 2004, para $37,29 \%$, no ano de 2006.

No que diz respeito à situação funcional, a maioria dos discentes que estão cursando os componentes currirulares dos dois primeiros anos de curso, declararam não exercer nenhum tipo de atividade remunerada. Já aqueles que estão do terceiro ano em diante, afirmaram que exercem algumas atividades em empresas privadas, na condição de estagiário ou assistentes. Os dados revelam que apesar da possibilidade de os mesmos poderem participar de progamas de monitoria, grupos de pesquisa e projetos de extensão, remunerados e/ou voluntários, poucos se envolvem efetivamente com essas atividades.

Pode-se afirmar que o nível de empregabilidade dos discentes, principalmente após o terceiro ano de curso, ocorre em razão da possibilidade dos mesmos poderem complementar os conhecimentos adquiridos em sala com atividades extracurriculares. Além disso, destaca-se a preocupação em buscar, durante o período de formação no curso de Ciências Contábeis, o exercício de atividades que lhes garanta uma maior aproximação à prática contábil (registro de eventos pessoal, fiscal e contábil) e ao campo de atuação profissional.

Em se tratando da motivação para escolha do curso, e considerando as mudanças ocorridas na forma de ingresso na UFERSA, com a implementação do SISU, observa-se a predominância de discentes que buscam: maiores possibilidades de aprovação em concurso público e boas oportunidades de emprego. Isso ocorre em razão da constate busca por estabilidade profissional e garantias trabalhistas, como retratado nos estudos de Rêgo e Andrade (2010) e Sá (2011).

\subsection{CONHECIMENTOS GERAIS SOBRE OS ATIVOS}

Analisando o posicionamento dos respondentes, observou-se que há algumas divergências de conhecimentos sobre a definição de ativo, bem como sobre o processo de reconhecimento, mensuração e evidenciação. Para tanto, foram considerados os discentes que efetivamente cursaram o componente curricular de "Teoria da Contabilidade" e os que ainda não chegaram nesse momento (Tabela 2). O referido componente, faz parte do eixo formativo profissional do curso de graduação em Ciências Contábeis da UFERSA e tem em sua ementa a previsão do tratamento das contas de ativo. O mesmo é oferecido aos discentes regularmente matriculados 
no quarto período e que já integralizaram os pré-requisitos de "Contabilidade introdutória" e "Contabilidade intermediária I" (PPC-CC, 2012).

Tabela 2: Conhecimentos sobre a definição de ativos

\begin{tabular}{l|c|c}
\hline & $\begin{array}{c}\text { Cursou Teoria da } \\
\text { Contabilidade }\end{array}$ & $\begin{array}{c}\text { Não cursou Teoria } \\
\text { da Contabilidade }\end{array}$ \\
\hline Recursos disponíveis, direitos e participações. & $7 \%$ & $15 \%$ \\
\hline $\begin{array}{l}\text { Recurso controlado pela entidade como resultado de } \\
\text { eventos passados e do qual se espera que fluam futuros } \\
\text { benefícios econômicos para a entidade. }\end{array}$ & $64 \%$ & $28 \%$ \\
\hline $\begin{array}{l}\text { Conjunto de bens e direitos controlados pela empresa. } \\
\begin{array}{l}\text { Potenciais fluxos de serviço ou direitos a benefícios } \\
\text { futuros sob o controle de uma organização. }\end{array}\end{array}$ & $12 \%$ & $53 \%$ \\
\hline
\end{tabular}

Fonte: Dados da pesquisa (2013).

Analisando as respostas obtidas quanto a definição dos ativos, observa-se que há divergências entre os posicionamentos dos discentes. Isso ocorre em razão daqueles que já cursaram a disciplina de "Teoria da Contabilidade" (64\%), seguirem os preceitos normativos apontados no CPC 00-R1 (2011) e os demais adotarem aspectos conceituais discutidos e apresentados nos primeios períodos do curso. Tal fato corrobora com o estudo de Lima Filho e Bruni (2012) em termos de maximização do domínio conceitual dos ativos, a partir dos avanços dos discentes no curso.

No que diz respeito ao processo de reconhecimento dos ativos, o estudo aponta que os mesmos seguem as orientações normativas do CPC, cujo papel consiste em propiciar o processo de convergência das práticas de reconhecimento dos ativos as normas internacionais, como pode ser visualizado na Tabela 3.

Tabela 3: Processo de reconhecimento dos ativos

\begin{tabular}{l|c|c}
\hline & $\begin{array}{c}\text { Cursou Teoria da } \\
\text { Contabilidade }\end{array}$ & $\begin{array}{c}\text { Não cursou } \\
\text { Teoria da } \\
\text { Contabilidade }\end{array}$ \\
\hline $\begin{array}{l}\text { Reconhecido quando for provável que benefícios } \\
\text { econômicos futuros dele provenientes fluirão para a } \\
\text { entidade e seu custo ou valor puder ser mensurado com } \\
\text { confiabilidade. }\end{array}$ & $59 \%$ & $68 \%$ \\
\hline $\begin{array}{l}\text { Reconhecido com base no fato gerador. } \\
\text { Reconhecido quando satisfaz a definição de ativo e passa } \\
\text { por testes de relevância e confiabilidade. }\end{array}$ & $22 \%$ & $21 \%$ \\
\hline
\end{tabular}

Fonte: Dados da pesquisa (2013).

Apesar de a maioria dos discentes compreenderem o reconhecimento dos ativos quando os benefícios econômicos futuros são provavéis e fluem para a entidade, percebe-se que os discentes que estão nos últimos anos de curso também seguem o que preceitua a "Teoria da Contabilidade" (HENDRIKSEN; VAN BREDA, 2009, NIYAMA; SILVA, 2011). Isso pode ter ocorrido em função da falta de oportunidade de discussão normativa sobre o assunto e em razão do CPC 00-R1 só 
ter sido publicado após os mesmos já terem cursado a disciplina. Tal fato aponta para a necessidade do corpo docente buscar por alternativas que permitam a discussão normativa, em sala, sobre as mudanças que vem ocorrendo no ambiente da Contabilidade, seja mediante à inclusão de componentes curriculares especiais ou a promoção de atividades extracurriculares (palestras, minicursos).

Segundo Goulart (2002), para que um ativo seja reconhecido no balanço, é necessário identificar a potencialidade de recebimento dos benefícios econômicos futuros, considerando bases confiáveis. Comparando os dados obtidos com o estudo de Sá (2011), observa-se que 45,12\% dos respondentes reconhecem os ativos como um recurso controlado pela entidade, que tem origem em eventos passados e que podem gerar benefícios futuros. Nessa perspectiva, o estudo revela que tanto os discentes que já cursaram a disciplina (59\%) de "Teoria da Contabilidade" como os demais $(68 \%)$, reconhecem as contas de ativo de forma semelhante. Quanto ao procedimento de mensuração dos ativos a ser considerado para elaboração dos relatórios (GUERREIRO et al., 2005), os dados revelam que os discentes tem compreensões distintas, de acordo com o posicionamento no curso, como pode ser visualizado na Tabela 4.

Tabela 4: Processo de mensuração dos ativos

\begin{tabular}{l|c|c}
\hline & $\begin{array}{c}\text { Cursou Teoria da } \\
\text { Contabilidade }\end{array}$ & $\begin{array}{c}\text { Não cursou } \\
\text { Teoria da } \\
\text { Contabilidade }\end{array}$ \\
\hline $\begin{array}{l}\text { Com base no valor justo, custo de aquisição (emissão ou } \\
\text { produção) e valor presente. }\end{array}$ & $31 \%$ & $21 \%$ \\
\hline $\begin{array}{l}\text { Com base no custo histórico, custo corrente, valor } \\
\text { realizável (valor de realização ou de liquidação) e valor } \\
\text { presente. }\end{array}$ & $44 \%$ & $34 \%$ \\
\hline $\begin{array}{l}\text { Com base no custo histórico. } \\
\begin{array}{l}\text { Com base em medidas de entrada (custo histórico, custo } \\
\text { de reposição, custos esperados) e de saída (preço de venda } \\
\text { passado, preço corrente de venda, valor realizável } \\
\text { esperado). }\end{array}\end{array} \quad 20 \%$ & $4 \%$ \\
\hline
\end{tabular}

Fonte: Dados da pesquisa (2013).

Os achados indicam que $44 \%$ os discentes que cursaram a disciplina de "Teoria da Contabilidade", compreendem a mensuração dos ativos sob a perspectiva do conteúdo do CPC 00-R1(2011). Entretanto, aqueles que ainda não cursaram, compreendem o processo de mensurção dos ativos sob a perspectiva teórica, como discutido por Hendriken e Van Breda (2009). Esses dados vão de encontro ao que foi observado no trabalho de Sá (2011), uma vez que 50\% dos respondentes compreendiam a mensuração sob a perspectiva de valor monetário ou quantitativo.

A partir dos aspectos discutidos e a necessidade de compreensão do que trata cada um deles para a tomada de decisão, o estudo aponta que os discentes assumem 
compreensões diversas sobre a quesão da evidenciação, independente de terem cursado ou não "Teoria da Contabilidade", como pode ser visualizado na Tabela 5.

Tabela 5: Processo de evidenciação dos ativos

\begin{tabular}{l|c|c}
\hline & $\begin{array}{c}\text { Cursou Teoria da } \\
\text { Contabilidade }\end{array}$ & $\begin{array}{c}\text { Não cursou } \\
\text { Teoria da } \\
\text { Contabilidade }\end{array}$ \\
\hline $\begin{array}{l}\text { Divulgar informações financeiras no Balanço, em ordem } \\
\text { decrescente de grau de liquidez dos elementos registrado } \\
\text { em ativo circulante e ativo não circulante. }\end{array}$ & $30 \%$ & $19 \%$ \\
\hline $\begin{array}{l}\text { Divulgar informações financeiras no Balanço patrimonial, } \\
\text { de modo a torná-la clara, concisa e compreensível. }\end{array}$ & $33 \%$ & $36 \%$ \\
\hline $\begin{array}{l}\text { Divulgar informações financeiras no Balanço patrimonial, } \\
\text { de acordo com grau de liquidez. }\end{array}$ & $21 \%$ & $23 \%$ \\
\hline $\begin{array}{l}\text { Divulgar informações financeiras úteis ao processo de } \\
\text { tomada de decisão. }\end{array}$ & $16 \%$ & $23 \%$ \\
\hline
\end{tabular}

Fonte: Dados da pesquisa (2013).

Os conhecimentos sobre a extensão de evidenciação, obrigatória e voluntária, requer cuidados, principalmente, quando se refere à transparência dos recursos investidos na composição dos ativos (AVELINO et al., 2012). Os dados apontam que tanto os discentes que cursaram a disciplina (33\%), como aqueles que não chegaram a esse estágio (36\%), seguem as perspectivas normativas previstas no CPC 00-R1 (2011). Comparativamente ao estudo de Sá (2011), observou-se que parte dos respondentes $(29,27 \%)$ apresentam uma compreensão voltada para a decisão financeira e a disseminação de informações que possam atender às necessidades dos mais diversos tipos de usuários.

O estudo aponta que a disciplina de "Teoria da Contabilidade" propicia aos discentes, em processo de formação, deter conhecimentos mais aprofundados sobre os ativos, sobretudo, quanto a sua definição e aos problemas de reconhecimento, mensuração e evidenciação. Apesar dos discentes não disporem de conhecimentos suficientes sobre os ativos, cabe frisar a necessidade dos mesmos deterem informações mais acuradas sobre o assunto, de modo a possibilitar uma atuação profissional mais condizente com a demanda da sociedade.

\subsection{CLASSIFICAÇÃO DOS ATIVOS}

Ponderando a respeito das respostas dadas pelos discentes que já cursaram o componente de "Teoria da Contabilidade", os dados revelam que alguns discentes tem dificuldade em classificar as contas patrimoniais pelo grau de liquidez, ativo circulante e ativo não circulante, como pode ser visualizado na Tabela 6. 
Tabela 6: Classificação anunciada pelos discentes (liquidez)

\begin{tabular}{|c|c|c|c|c|c|c|}
\hline & \multicolumn{3}{|c|}{$\begin{array}{c}\text { Cursou Teoria da } \\
\text { Contabilidade }\end{array}$} & \multicolumn{3}{|c|}{$\begin{array}{c}\text { Não cursou Teoria da } \\
\text { Contabilidade }\end{array}$} \\
\hline & $\mathrm{AC}^{*}$ & $\mathrm{ANC}^{* *}$ & NSA $^{* * *}$ & $\mathrm{AC}^{*}$ & $\mathrm{ANC}^{* *}$ & NSA $^{* * *}$ \\
\hline Adiantamentos a empregados & $42 \%$ & $7 \%$ & $51 \%$ & $40 \%$ & $15 \%$ & $45 \%$ \\
\hline Caixa & $94 \%$ & $5 \%$ & $1 \%$ & $94 \%$ & $4 \%$ & $2 \%$ \\
\hline Capital social & $13 \%$ & $17 \%$ & $70 \%$ & $32 \%$ & $28 \%$ & $40 \%$ \\
\hline Contas a receber & $83 \%$ & $8 \%$ & $9 \%$ & $81 \%$ & $17 \%$ & $2 \%$ \\
\hline Custo das mercadorias vendidas & $32 \%$ & $5 \%$ & $63 \%$ & $49 \%$ & $17 \%$ & $34 \%$ \\
\hline Despesas com salários e ordenados & $19 \%$ & $7 \%$ & $74 \%$ & $30 \%$ & $17 \%$ & $53 \%$ \\
\hline Devoluções de vendas & $27 \%$ & $16 \%$ & $57 \%$ & $34 \%$ & $28 \%$ & $38 \%$ \\
\hline Fornecedores & $21 \%$ & $16 \%$ & $63 \%$ & $36 \%$ & $24 \%$ & $40 \%$ \\
\hline Imóveis & $12 \%$ & $79 \%$ & $9 \%$ & $19 \%$ & $72 \%$ & $9 \%$ \\
\hline Juros ativos & $40 \%$ & $22 \%$ & $38 \%$ & $53 \%$ & $19 \%$ & $28 \%$ \\
\hline Marcas e patentes & $10 \%$ & $76 \%$ & $14 \%$ & $19 \%$ & $66 \%$ & $15 \%$ \\
\hline Obrigações trabalhistas a pagar & $20 \%$ & $16 \%$ & $64 \%$ & $28 \%$ & $25 \%$ & $47 \%$ \\
\hline Receitas antecipadas & $38 \%$ & $14 \%$ & $48 \%$ & $57 \%$ & $13 \%$ & $30 \%$ \\
\hline Reservas de capital & $14 \%$ & $19 \%$ & $67 \%$ & $43 \%$ & $30 \%$ & $27 \%$ \\
\hline Tributos sobre vendas & $22 \%$ & $14 \%$ & $64 \%$ & $40 \%$ & $28 \%$ & $32 \%$ \\
\hline Veículos & $9 \%$ & $83 \%$ & $8 \%$ & $26 \%$ & $68 \%$ & $6 \%$ \\
\hline
\end{tabular}

${ }^{*}$ AC: Ativo circulante. ${ }^{* *}$ ANC: Ativo não circulante. ${ }^{* * *}$ NSA: Não se aplica.

Fonte: Dados da pesquisa (2013).

Analisando os dados obtidos com os discentes que já cursaram "Teoria da Contabilidade", observa-se que os mesmos tem dificuldades em classificar corretamente algumas contas de ativo circulante como "Adiantamento a empregados" (58\%). Além disso, alguns discentes parecem não saber separar as contas patrimoniais e de resultado, classificando equivocadamente a conta de "Custo das mercadorias vendidas", como ativo circulante (32\%) ou não circulante (5\%). Observou-se, ainda, que a conta de "Juros ativos" também causou confusão para os discentes, que a classificaram erroneamente como um ativo circulante $(40 \%)$ e não como uma conta de resultado, pertecente ao grupo de receitas financeiras.

No que diz respeito à classificação da conta de "Receitas antecipadas" (52\%), destaca-se que a mesma não sinaliza bens ou direitos, mas representam obrigações de entrega de mercadorias ou prestação de serviços no futuro, sendo devidamente registrada como uma conta de passivo circulante. O mais interessante é que apesar dos imóveis $(21 \%)$, marcas e patentes $(23 \%)$, veículos $(17 \%)$, caixa $(6 \%)$ e contas a receber $(17 \%)$ sinalizarem contas de ativo, alguns discentes apresentaram dificuldades em definir qual a natureza dos itens analisados, o que sugere a necessidade de se reforçar a importância do conhecimento das contas para os registros contábeis

Analisando as respostas dos discentes que não cursaram o componente curricular de "Teoria da Contabilidade", os dados indicam que alguns deles tem dificuldade em classificar as contas patrimoniais em ativo circulante e ativo não circulante. Quando se trata dos discentes que ainda não cursaram a disciplina de 
"Teoria da Contabilidade", observa-se que os mesmos também tem dificuldades em classificar as contas. A conta de ativo circulante, "Adiantamento a empregados" $(60 \%)$, foi classificada de forma equivocada, ao passo em que esses discentes demonstram reconhecer as contas de "Caixa" (94\%) e "Contas a receber" (81\%) de forma mais adequada. No que diz respeito ao ativo não circulante, o estudo aponta que $32 \%$ dos discentes não reconhecem o imobilizado referente à conta "Veículos" e $28 \%$ tem dificuldade em classificar, adequadamente, a conta de "Imóveis". O mesmo foi percebido com relação ao intangível referente as "Marcas e patentes" (34\%).

Os achados apontam que $70 \%$ dos discentes não reconhecem a conta de "Receitas antecipadas" como uma obrigação para a empresa, mas como um direito. Os discentes também apresentaram dificuldades em relação à classificação adequada das contas de patrimônio líquido, "Capital social" (60\%) e "Reserva de capital" (72\%). Os discentes ainda não reconhecem de forma adequada as contas de resultado: "Custos das mercadorias vendidas" (76\%), "Despesas com salários e ordenados" (47\%), "Juros ativos" (72\%).

Fazendo uma analogia entre as respostas dos entrevistados, adverte-se que os discentes tiveram a mesma compreensão a respeito da conta "Caixa" (94\%) classificando corretamente em ativo circulante. Já quanto a classificação do item "Contas a receber", constata-se que os discentes tem conhecimentos equivalentes, independentemente se cursaram (83\%) ou não (81\%) a disciplina. Os discentes que cursaram a disciplina de "Teoria da Contabilidade" classificaram de forma mais adequada o item de "Marcas e Patentes" (77\%), ao passo que os demais tiveram um pouco mais de dificuldade com essa classificação (44\%). Já em relação a "Receita antecipada" pode-se afirmar que tanto os discentes que cursaram a disciplina (48\%), como os demais (30\%) tem dificuldades em classificá-la corretamente.

Quando se trata das respostas dadas em relação à tangibilidade (SQUENA; PASUCH, 2010), o estudo aponta que os discentes tem dificuldades em reconhecer adequadamente os itens de ativo, como pode ser visualizado na Tabela 7.

Tabela 7: Classificação anunciada pelos discentes (tangibilidade)

\begin{tabular}{|c|c|c|c|c|c|c|}
\hline & \multicolumn{3}{|c|}{$\begin{array}{l}\text { Cursou Teoria da } \\
\text { Contabilidade }\end{array}$} & \multicolumn{3}{|c|}{$\begin{array}{c}\text { Não cursou Teoria da } \\
\text { Contabilidade }\end{array}$} \\
\hline & TAN* & INT $^{* *}$ & $\mathbf{N S A}^{* * *}$ & TAN* & INT** $^{* *}$ & NSA $^{* * *}$ \\
\hline Adiantamentos a empregados & $41 \%$ & $15 \%$ & $44 \%$ & $40 \%$ & $17 \%$ & $43 \%$ \\
\hline Caixa & $79 \%$ & $16 \%$ & $5 \%$ & $87 \%$ & $4 \%$ & $9 \%$ \\
\hline Capital social & $38 \%$ & $10 \%$ & $52 \%$ & $60 \%$ & $14 \%$ & $26 \%$ \\
\hline Contas a receber & $60 \%$ & $26 \%$ & $14 \%$ & $68 \%$ & $26 \%$ & $6 \%$ \\
\hline Custo das mercadorias vendidas & $31 \%$ & $16 \%$ & $53 \%$ & $47 \%$ & $23 \%$ & $30 \%$ \\
\hline Despesas com salários e ordenados & $25 \%$ & $16 \%$ & $59 \%$ & $38 \%$ & $19 \%$ & $43 \%$ \\
\hline Devoluções de vendas & $38 \%$ & $11 \%$ & $51 \%$ & $51 \%$ & $15 \%$ & $34 \%$ \\
\hline Fornecedores & $36 \%$ & $10 \%$ & $54 \%$ & $49 \%$ & $21 \%$ & $30 \%$ \\
\hline Imóveis & $73 \%$ & $19 \%$ & $8 \%$ & $70 \%$ & $26 \%$ & $4 \%$ \\
\hline Juros ativos & $33 \%$ & $37 \%$ & $30 \%$ & $47 \%$ & $25 \%$ & $28 \%$ \\
\hline Marcas e patentes & $15 \%$ & $70 \%$ & $15 \%$ & $7 \%$ & $91 \%$ & $2 \%$ \\
\hline
\end{tabular}




\begin{tabular}{l|c|c|c|c|c|c}
\hline Obrigações trabalhistas a pagar & $21 \%$ & $25 \%$ & $54 \%$ & $47 \%$ & $21 \%$ & $32 \%$ \\
\hline Receitas antecipadas & $37 \%$ & $20 \%$ & $43 \%$ & $56 \%$ & $23 \%$ & $21 \%$ \\
\hline Reservas de capital & $23 \%$ & $26 \%$ & $51 \%$ & $54 \%$ & $23 \%$ & $23 \%$ \\
\hline Tributos sobre vendas & $28 \%$ & $23 \%$ & $49 \%$ & $45 \%$ & $30 \%$ & $25 \%$ \\
\hline Veículos & $75 \%$ & $19 \%$ & $6 \%$ & $81 \%$ & $17 \%$ & $2 \%$ \\
\hline
\end{tabular}

* TAN: Tangível. ** INT: Intangível. *** NSA: Não se aplica.

Fonte: Dados da pesquisa (2013).

Os discentes que já cursaram a disciplina de "Teoria da Contabilidade", apresentaram problemas em reconhecer as contas de "Imóveis" (27\%) e "Veículos" de forma adequada (25\%), embora esses representem tangíveis clássicos, que possuem forma física. Do mesmo modo, percebe-se que as dificuldades com a classificação dos ativos tangíveis persiste, com as contas de "Adiantamentos a empregados" (85\%) e "Contas a receber" $(84 \%)$, que representam direitos e não possuem forma física.

Destaca-se que alguns discentes não reconhecem as contas "Capital social" (48\%) e "Reserva de capital" $(49 \%)$ como contas de patrimônio líquido, mas como ativos. Além das contas de passivo "Fornecedores" (46\%) e "Ordenados e salários a pagar" (46\%). Constatou-se ainda que esses discentes tem poblemas em reconhecer as contas de resultado "Despesas com salários e ordenados" (41\%), "Juros ativos" (70\%) e "Devoluções de vendas" (49\%).

Os discentes que não cursaram o componente curricular de "Teoria da Contabilidade", tem dificuldades quanto à tangibilidade dos itens. Analisando as respostas daqueles que ainda não cursaram "Teoria da Contabilidade", observa-se que eles detêm conhecimentos mais aprofundados quanto aos itens tangíveis, tais como "Veículos" (81\%), apesar de alguns deles ainda terem problemas em reconhecer os "Imóveis" (30\%). Os discentes reconhecem como intangíveis, a conta de "Marcas e patentes" (91\%), como previsto no Plano de contas. Apesar disso, os demais intangíveis não receberam o tratamento adequado durante o processo de classificação: "Adiantamento a empregados" (83\%) e "Contas a receber" (81\%).

Percebe-se ainda que o problema com a classificação das contas de patrimônio líquido persiste, "Capital social" (74\%) e "Reservas de capital" (77\%). Além disso, as contas de resultado também receberam tratamento equivocado, "Juros ativos" (72\%), “Tributos sobre vendas" (74\%), "Despesas com salários e ordenados" (57\%). No que diz respeito à questão da tangibilidade, observa-se que os discentes que cursaram a referida disciplina $(60 \%)$ não compreendem corretamente a classificação do ativo circulante de "Contas a Receber", assim como aqueles que ainda não tiveram a oportunidade de cursá-la (68\%).

Considerando os resultados obtidos, constata-se que os discentes precisam conhecer melhor o "Plano de contas", de modo que possam classificar adequadamente cada item, principalmente quando se trata em diferenciar as contas patrimoniais e de resultado. O problema é que essa diferença elementar prejudica a adequada classificação dos ativos (circulante, não circulante, tangível, intangível) e a 
percepção dos usuários sobre a situação da organização (SQUENA; PASUCH, 2010). Cabe aos docentes o papel de explorar esse assunto desde as primeiras disciplinas do curso, uma vez que a classificação equivocada prejudica a disposição das contas nos demonstrativos e consequentemente o proceso de tomada de decisão por parte dos usuários (LIMA FILHO; BRUNI, 2012).

\section{CONSIDERAÇÕES FINAIS}

O estudo objetivou investigar qual a concepção dos discentes do curso de graduação em Ciências Contábeis da UFERSA sobre os ativos. Para isso, utilizou-se das prerrogativas discutidas por Goulart (2002), bem como do que reza à teoria e as normas inerentes às práticas contábeis. Nesse contexto, analisaram-se elementos pertinentes aos ativos, tais como: definição, reconhecimento, mensuração, evidenciação e classificação.

Em relação ao perfil dos entrevistados, os resultados demostraram que a maioria dos respondentes são do gênero feminino e possuem de 16 a 24 anos. Destaca-se que esse público jovem não exerce nenhuma atividade remunerada e que a maioria dos discentes escolheu o curso em razão das perspectivas de empregabilidade e ingresso em cargos públicos que requerem concurso.

Aqueles que cursaram a disciplina de "Teoria da Contabilidade", comprendem a definição de ativos, o processo de mensuração e evidenciação sob a perspectiva do CPC 00-R1 (2011). Isso revela a preocupação dos docentes em ministrar seus conteúdos, observando não só a teoria, mas o que preceitua as normas internacionais. Já em relação as questões de reconhecimento dos ativos ocorre o inverso, e os aspectos normativos internacionais são sobrepostos pelas discussões advindas da teoria.

Os discentes que ainda não cursaram a disciplina de "Teoria da Contabilidade" possuem uma concepção mais objetiva sobre os ativos. Isso ocorre em razão dos docentes estarem mais preocupados em simplificar conceitos e discutir apenas o que é tratado em livros de "Contabilidade Introdutória" e "Contabilidade Básica". No que concerne ao processo de reconhecimento e mensuração dos ativos, destaca-se a sua compreesão seguindo a perspectiva teórica, ao passo que o tratamento da evidenciação segue o CPC 00-R1.

No que diz respeito à classificação dos ativos, os respondentes apresentam dificuldades em separar as contas patrimoniais e de resultado, principalmente em relação aos itens que compõem o "Patrimônio líquido". Os dados revelam a necessidade de se discutir questões de tangibilidade quanto aos itens patrimoniais, mediante a realização de maiores discussões em sala de aula. Além disso, requer um maior aprofundamento sobre o processo de registro das atividades operacionais da organização e a composição ideal para o "Plano de contas": elenco das contas, 
manual de contas (função, funcionalidade e natureza) e modelos padronizados das demonstrações.

Os dados apontam que a concepção dos discentes do curso de graduação em Ciências Contábeis da UFERSA sobre os ativos, se modifica de acordo com o posicionamento no curso. Diante disso, recomenda-se que sejam realizados novos estudos sob a mesma perspectiva, junto às outras IES de Mossoró/RN, de modo a identificar se há mudanças significativas de acordo com a proposta formativa do curso. Um estudo semelhante pode ser realizado com os profissionais já formados e que atuam na região. Além disso, sugere-se que sejam realizados trabalhos com a finalidade de identificar a compreensão dos discentes com relação aos demais itens do Plano de contas (patrimoniais e de resultado), apesar dessa discussão ser mais apropriada em instrumentos de avaliação acadêmica, do que em pesquisas científicas.

\section{REFERÊNCIAS}

ASSAF NETO, A. Estrutura e análise de balanços: um enfoque econômicofinanceiro. 9ª ed. São Paulo, Atlas, 2010.

AVELINO, B. C.; PINHEIRO, L. E. T.; LAMOUNIER, W. M. Evidenciação de ativos intangíveis: estudo empírico em companhias abertas. Revista de Contabilidade e Organizações, Ribeirão Preto, vol. 6, n. 14, jan./abr. 2012, pp. 23-45.

BRASIL. Lei das sociedades por Ações, Lei n.o 6.404, de 15 de dezembro de 1976. Dispõe sobre as sociedades por ações. Disponível em: http://www.planalto.gov.br/ccivil 03/Leis/L6404consol.htm. Acesso em: 20 mar. 2013.

Lei n. ${ }^{\circ}$ 11.638, 28 de dezembro de 2007, Altera e revogam dispositivos da Lei $n^{\circ}$ 6.404, de 15 de Dezembro de 1976, e da Lei nº 6.385, de 7 de dezembro de 1976, e estende às sociedades de grande porte disposições relativas à elaboração e divulgação de demonstrações financeiras. Disponível em: http://www.planalto.gov.br/ccivil 03/ ato2007-2010/2007/lei/111638.htm. Acesso em: 02 abr. 2011.

CARVALHO, R. M. F.; LIMA, D. V.; FERREIRA, L. O. G. Processo de Reconhecimento e Mensuração do Ativo Imobilizado no Setor Público Face aos Padrões Contábeis Internacionais: um estudo de caso na Anatel. Revista Universo Contábil, Blumenau, vol. 8, n. 3, jul./set. 2012, pp. 62-81.

CFC. Conselho Federal de Contabilidade. Quantos Somos/Dados Estatísticos. Disponível em: 
http://portalcfc.org.br/coordenadorias/registro/cadastro/quantos somos. Acesso em: 10 jul. 2013.

CPC. Comitê de Pronunciamento Contábeis. CPC 00-R1 - Pronunciamento Conceitual Básico - Estrutura Conceitual para a Elaboração e Apresentação das Demonstrações Contábeis. Disponível em: http://www.cpc.org.br/pdf/pronunciamento conceitual.pdf. Acesso em: 10 jul. 2013.

. Pronunciamento Técnico CPC 01-R1 - Redução ao Valor Recuperável de Ativos. Disponível em: http://www.cpc.org.br/pdf/pronunciamento conceitual.pdf. Acesso em: 10 jul. 2013.

. Pronunciamento Técnico CPC 04-R1 - Ativo Intangível. Disponível em: http://www.cpc.org.br/pdf/pronunciamento conceitual.pdf. Acesso em: 10 jul. 2013.

Contábeis.

Pronunciamento Técnico CPC 26-R1 - Apresentação das Demonstrações http://www.cpc.org.br/pdf/pronunciamento conceitual.pdf. Acesso em: 10 jul. 2013.

DIEHL, A. A.; TATIM, D. C. Pesquisa em ciências sociais aplicadas: métodos e técnicas. São Paulo, Prentice-Hall, 2004.

FERREIRA, R. J. Contabilidade básica: finalmente você vai aprender Contabilidade. $7^{a}$ ed. Rio de Janeiro, Ferreira, 2009.

GOULART, A. M. C. O Conceito de Ativos na Contabilidade: um fundamento a ser explorado. Revista Contabilidade \& Finanças da USP, São Paulo, vol. 13, n. 28, jan./abr. 2002, pp.56-65.

GUERREIRO, R.; CROZATI, J.; RIBEIRO, M. S. Mensuração de ativos nos relatórios gerenciais de companhias abertas. Revista de Gestão USP, São Paulo, vol. 12, n. 3, jul./set. 2005, pp. 91-107.

HENDRIKSEN, E. S.; VAN BREDA, M. F. Teoria da Contabilidade. São Paulo, Atlas, 2009.

IUDÍCIBUS, S. Teoria da Contabilidade. 9ª ed. São Paulo, Atlas, 2009.

LIMA FILHO, R. N.; BRUNI, A. L. Percepção dos graduandos em Ciências Contábeis de Salvador (BA) sobre os conceitos relevantes da Teoria da Contabilidade. Revista de Educação e Pesquisa em Contabilidade, Brasília, vol. 6, n. 2, abr./jun. 2012, pp. 187-203. 
LUSTOSA, P. R B. Ativo e sua avaliação. In: RIBEIRO FILHO, J. F.; LOPOES, J.; PEDERNEIRAS, M. (org.). Estudando teoria da Contabilidade. São Paulo, Atlas, 2009, pp. 88-89.

MALHOTRA, N. K. Pesquisa de marketing: foco na decisão. $3^{\underline{a}}$ ed. São Paulo, Pearson Prentice Hall, 2011.

MARION, J. C. Contabilidade empresarial. 15ª ed. São Paulo, Atlas, 2009.

MARION, J. C.; REIS, A. C. R. Contabilidade avançada: para concursos públicos e cursos de graduação em ciências contábeis. São Paulo, Saraiva, 2006.

MORIN, E. Os sete saberes necessários à educação do futuro. 2ª ed. São Paulo, UNESCO, 2000.

NIYAMA, J. K.; SILVA, C. A. T. Teoria da Contabilidade. $2^{\underline{a}}$ ed. São Paulo, Atlas, 2011.

OTT, E; PIRES, C. B. Conceito e objetivo da Contabilidade. In: RIBEIRO FILHO, J. F.; LOPOES, J.; PEDERNEIRAS, M. (org.). Estudando teoria da Contabilidade. São Paulo, Atlas, 2009, pp. 58.

PPC. Projeto Pedagógico de Curso do Curso de Graduação em Ciências Contábeis, 2012

http://www2.ufersa.edu.br/portal/view/uploads/setores/200/PPC\%202012.pdf.

Acesso em: 10 jul. 2013.

PEREZ, M. M.; FAMÁ, R. Ativos intangíveis e o desempenho empresarial. Revista Contabilidade \& Finanças - USP, São Paulo, vol. 17, n. 40, jan./abr. 2006, pp. 7-24.

PONTE, V. M. R.; DE LUCA, M. M. M.; SOUSA, H. V.; CAVALCANTE, D. S. Práticas de Divulgação do Teste de Redução ao Valor Recuperável de Ativos pelas Companhias Abertas Listadas na BM\&FBOVESPA. Revista Contabilidade Vista \& Revista, Belo Horizonte, vol. 22, n. 4, out./dez. 2011, pp. 113-144.

RAMPAZZO, L. Metodologia científica: para alunos dos cursos de graduação e pósgraduação. 3ํㅡㄹ. ed. São Paulo, Loyola, 2005.

RÊGO, T. F.; ANDRADE, E. R. G. Perfil e campo de atuação profissional dos egressos do Curso de Ciências Contábeis da UFRN. Revista Ambiente Contábil, Natal, vol. 2, n. 2, jul./dez. 2010, pp.1-17. 
RIBEIRO, O. M. Contabilidade intermediária. 2ª ed. São Paulo, Atlas, 2009a.

RIBEIRO, O. M. Contabilidade básica fácil. 26ª ed. São Paulo, Saraiva, 2009b.

SÁ, F. S. Definição de ativos segundo a teoria contábil: um estudo sobre a concepção dos estudantes de graduação em ciências contábeis das IFES públicas do estado da Paraíba. 2011. 62 f. Monografia (Curso de Ciências Contábeis). Universidade Federal de Campina Grande. Sousa-PB, 2011.

SAMARA, B. S.; BARROS, J. C. Pesquisa de Marketing: Conceitos e Metodologia. São Paulo, Pearson, 2002.

SILVA, E. L.; MENEZES, E. M. Metodologia da pesquisa e elaboração de dissertação. $4^{\mathrm{a}}$ ed. rev. atual. Florianópolis, UFSC, 2005.

SQUENA, R.; PASUCH, D. F. Goodwill: sua definição e relevância para a área contábil. Revista Gestão Organizacional, Chapecó, vol. 3, n. 1, jan./jun. 2010, pp. 4457.

SZUSTER, N.; CARDOSO, R. L.; SZUSTER, F. R.; SZUSTER, F. R.; SZUSTER, F. R. Contabilidade geral: introdução à Contabilidade societária. $4^{a}$ ed. São Paulo: Atlas, 2010.

VASCONCELOS, Y. L.; VIANA, A. L. Evidenciação: forma e qualidade. Revista do Conselho Federal de Contabilidade, Brasília, n. 134, mar./abr. 2002, pp. 21-29. 